\title{
Oesophageal epithelial innervation in health and reflux oesophagitis
}

\author{
M Newton, M A Kamm, P O Soediono, P Milner, W R Burnham, G Burnstock
}

\begin{abstract}
Background-The response of the oesophagus to refluxed gastric contents is likely to depend on intact neural mechanisms in the oesophageal mucosa. The epithelial innervation has not been systematically evaluated in health or reflux disease.

Aims-To study oesophageal epithelial innervation in controls, and also inflamed and non-inflamed mucosa in patients with reflux oesophagitis and healed oesophagitis.
\end{abstract}

Patients-Ten controls, nine patients with reflux oesophagitis, and five patients with healed oesophagitis.

Methods-Oesophageal epithelial biopsy specimens were obtained at endoscopy. The distribution of the neuronal marker protein gene product 9.5 (PGP), and the neuropeptides calcitonin gene related peptide (CGRP), neuropeptide Y (NPY), substance $P(S P)$, and vasoactive intestinal peptide (VIP) were investigated by immunohistochemistry. Density of innervation was assessed by the proportion of papillae in each oesophageal epithelial biopsy specimen containing immunoreactive fibres (found in the subepithelium and epithelial papillae, but not penetrating the epithelium).

Results-The proportion of papillae positive for PGP immunoreactive nerve fibres was significantly increased in inflamed tissue when compared with controls, and non-inflamed and healed tissue. There was also a significant increase in VIP immunoreactive fibres within epithelial papillae. Other neuropeptides showed no proportional changes in inflammation.

Conclusions-Epithelial biopsy specimens can be used to assess innervation in the oesophagus. The innervation of the oesophageal mucosa is not altered in non-inflamed tissue of patients with oesophagitis but alters in response to inflammation, where there is a selective increase (about three- to fourfold) in VIP containing nerves.

(Gut 1999;44:317-322)

Keywords: gastro-oesophageal reflux; reflux oesophagitis; innervation; neuropeptides; inflammation

When gastric contents come into contact with the oesophageal mucosa a variety of sensorimotor reflexes are elicited which serve to enhance epithelial protection. These include: (1) increased salivary secretion $^{1-3} ;$ (2) epithelial bicarbonate $^{4-6}$ and mucus ${ }^{4-11}$ secretion; (3) increased epithelial blood flow ${ }^{12} ;(4)$ increased cell turnover, to maintain a cell barrier ${ }^{13-15}$; (5) reflex maintenance of lower oesophageal sphincter pressure ${ }^{16-22}$; and (6) oesophageal motor clearance of refluxed gastric contents. ${ }^{23-25}$

These reflexes are intimately dependent on intact sensory processing from the mucosa, and the production of an effector response at the mucosal level. The epithelial neural innervation is therefore of central importance in protecting the oesophagus. We hypothesised that this innervation may be impaired in patients with reflux oesophagitis, and have therefore evaluated these epithelial nerves. Changes in the oesophageal epithelial innervation have been shown in experimental oesophagitis in animals. ${ }^{26}$ It was intended to see whether this type of study could be done in the clinical setting using oesophageal epithelial biopsy specimens obtained at endoscopy before and after treatment of oesophagitis, and to compare findings with those in controls.

\section{Materials and methods}

SUBJECTS

Oesophageal epithelial biopsy specimens were obtained from three groups of patients.

Normal control biopsy specimens were obtained from asymptomatic patients $(n=10$, three men; median age 70 years, range $33-85$ ) referred for endoscopy for the investigation of iron deficiency anaemia. Biopsy specimens were taken only after the upper gastrointestinal tract had been examined endoscopically and found to be completely normal.

Patients with symptoms suggestive of gastrooesophageal reflux, who at endoscopy were found to have mild to moderate erosive oesophagitis (Savary Millar Grades I or $\mathrm{II}^{27}$ ) had biopsy specimens taken from the lower oesophagus, from areas of epithelial inflammation between actual erosions $(n=9$, four men; median age 60 years, range 45-78). Biopsy specimens were also taken in these patients from the non-inflamed normal oesophagus above the inflammation.

Biopsy specimens were obtained from different patients $(n=5$, one man; median age 59 years, range 45-66) with previously endoscopically proved grade II reflux oesophagitis who had been treated for eight weeks with $40 \mathrm{mg}$ omeprazole (Astra, Hassle, Sweden) orally

Abbreviations used in this paper: CGRP, calcitonin gene related peptide; GORD, gastro-oesophageal reflux disease; NPY, neuropeptide Y; PGP, protein gene product 9.5 ; SP, substance $\mathrm{P}$; VIP, vasoactive intestinal polypeptide; PBS, phosphate buffered saline; FITC, fluorescein isothiocyanate.
Accepted for publication 20 February 1998 


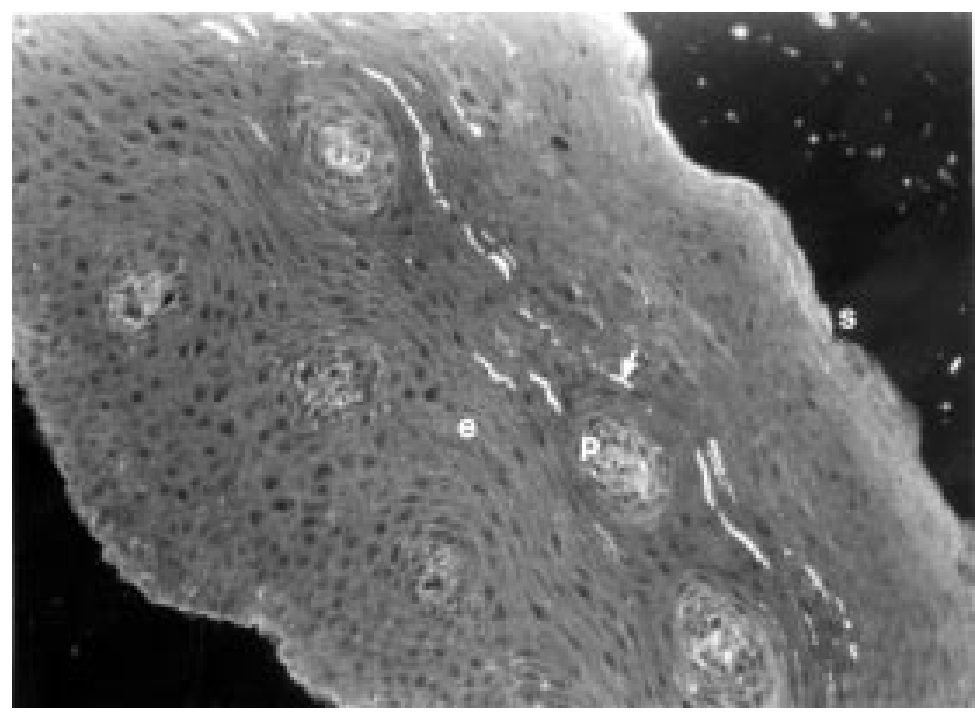

Figure 1 A photomicrograph of an oesophageal biopsy section from the inflamed oesophageal epithelium from a subject with reflux oesophagitis stained for PGP. The luminal surface is indicated $(s)$. The papillae ( $p$ ) extend into the epithelium (e). Immunofluorescent staining is seen in the subepithelial plexus extending across the upper poles of most of the papillae (arrow). Original magnification $\times 200$.

each morning. These specimens were taken at the time of second endoscopy when complete epithelial healing was confirmed while the patient was still taking omeprazole.

Oesophageal epithelial biopsy specimens were used because in this way repeat specimens could be obtained in a clinical setting - that is, before and after treatment of oesophagitis.

METHODS

Biopsy specimens were taken using pinch endoscopy biopsy forceps (Keymed, Southend-on-Sea, Essex, UK). Immediately after removal specimens were fixed in $4 \%$ (wt/ vol) paraformaldehyde in phosphate buffered saline (PBS, $\mathrm{pH}$ 7.4) for two hours at room temperature. Samples were then washed in 7\% (wt/vol) sucrose in PBS containing $0.1 \%$ (wt/vol) sodium azide and stored at $4^{\circ} \mathrm{C}$ for at least 18 hours in the same solution.

Samples were mounted in embedding medium (Tissue-Tek OCT compound, Miles Inc., USA) and $10 \mu \mathrm{m}$ sections cut on a cryostat (Reichart-Jung, Germany) at $-25^{\circ} \mathrm{C}$. From each biopsy specimen over 25 separate sections were cut, allowing at least five sections for each nerve marker studied. Sections were thaw mounted on gelatine coated slides and incubated separately in humid chambers at room temperature for 16 hours with rabbit polyclonal antisera, diluted $1 / 3000$, to protein gene product 9.5 (PGP 9.5, Ultraclone, Wellow, Isle of Wight, UK), calcitonin gene related peptide (CGRP, Affiniti, Technology Drive, Nottingham, UK), neuropeptide Y
(NPY, UCB Bioproducts, Chemide Foriest, B-1420 Braine-L'Alleud, Belgium), substance P (SP, Genesis, Milton Keynes, UK), and vasoactive intestinal polypeptide (VIP, INC, UK). Samples were then washed three times in PBS and incubated with biotin conjugated goat antirabbit immunoglobulin (Amersham, UK) at a dilution of $1 / 250$ for one hour. The sites of antigen-antibody binding were revealed by incubation with streptavidin-fluorescein isothiocyanate (FITC) conjugate (Amersham, UK) diluted $1 / 100$ for one hour. The preparations were washed, mounted with Citifluor (City University, London, UK) and viewed using a Zeiss microscope (Oberkochen, Germany). Selected areas were photographed with Kodak Tmax 3200 film.

The four neuropeptides selected for study are among the best represented in the gastrointestinal tract, especially the oesophagus. Substance $P$ and CGRP are likely to be involved in sensory processing, and VIP and NPY are involved in the motor responses; hence we felt that they represented the greatest chance of showing an abnormality in patients with reflux oesophagitis.

\section{DENSITY OF INNERVATION}

The oesophageal mucosa consists of squamous epithelium with underlying lamina propria. Papillae project from the lamina propria into the epithelium. The small size of the biopsy specimens and the absence of the lamina propria in some samples precluded the use of quantitative image analysis. A heterogeneous distribution of neuropeptide immunoreactivity within the lamina propria has previously been reported by others. ${ }^{28} 29$

There was a sparse distribution of fibres immunoreactive to some of the neuropeptides which meant that absolute counts of fibres may have been unreliable. Biopsy specimens were therefore quantitatively assessed by dividing the number of papillae containing immunoreactive fibres by the total number of papillae visible within each section, and expressing the result as a percentage. An increase in papilla length has been noted in oesophageal epithelial biopsy specimens from patients with oesophagitis. ${ }^{30}$ Biopsy sections which had no visible papillae were not included in this analysis, even if immunoreactive fibres were present in the lamina propria. Only those papillae whose base was present were counted. Specimens therefore had to have at least a small amount of lamina propria present to ensure that the subepithelial nerves had not been disrupted. Shorter papillae were therefore included with equal likelihood as the longer ones seen in inflamed oesophageal mucosa. In order

Table 1 Percentage of papillae containing fibres immunoreactive to the relevant antibody

\begin{tabular}{|c|c|c|c|c|c|}
\hline & $P G P$ & $C G R P$ & $N P Y$ & $S P$ & $V I P$ \\
\hline Controls $(n=10)$ & $29.7(12.5)$ & $11.8(7.2)$ & $28.6(5.6)$ & $13.5(6.9)$ & $12.4(7.3)$ \\
\hline Non-inflamed mucosa $(n=9)$ & $24 \quad(23.7)$ & $3.2(3.1)$ & $37.5(21.9)$ & $21.5(16.1)$ & $2.7(1.2)$ \\
\hline Healed mucosa $(n=5)$ & $42.9(17.6)$ & $0.5(0)$ & $0.5(0.3)$ & $3.1(1)$ & $11 \quad(5.6)$ \\
\hline Inflamed mucosa $(n=9)$ & $62.3(12)^{\star}$ & $13.8(6.9)$ & $43.6(13.5)$ & $22.6(7.8)$ & $52.8(12)^{\star}$ \\
\hline
\end{tabular}

Results are expressed as mean (SEM).

$\star$ Significant difference $(\mathrm{p}<0.05)$ when compared with the control, non-inflamed, and healed groups. 

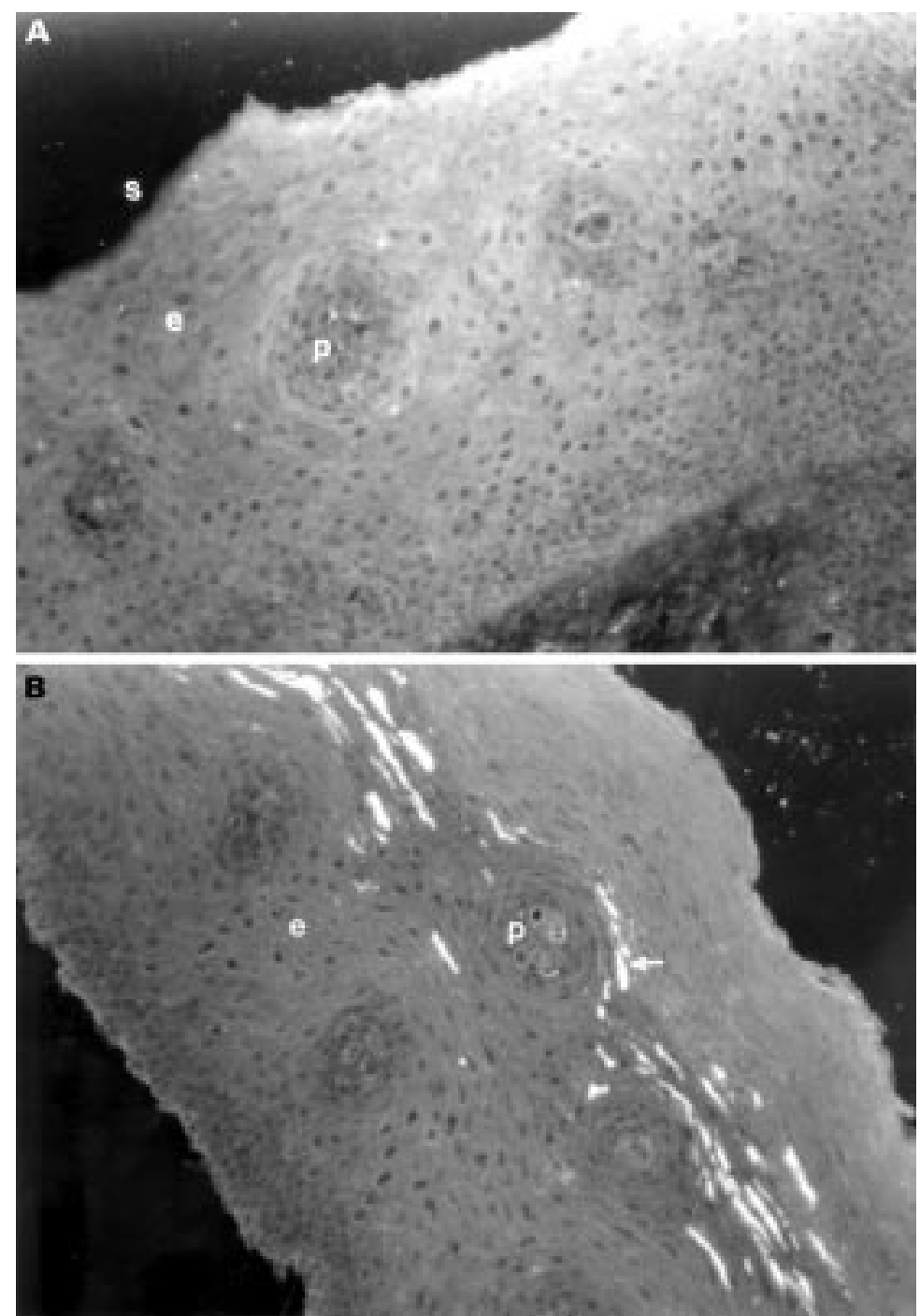

Figure 2 (A) Photomicrograph of an oesophageal biopsy section from control tissue stained for VIP. The luminal surface is indicated (s). The papillae ( $p)$ extend into the epithelium (e). There are no nerves staining positive for VIP in this biopsy specimen. (B) Photomicrograph of an oesophageal biopsy section from the inflamed oesophageal epithelium of a subject with reflux oesophagitis stained for VIP. The papillae ( $p)$ extend into the epithelium (e). Immunofluorescent staining is seen in the subepithelial plexus extending across the upper poles of most of the papillae (arrow). Original magnification $\times 200$.

to eliminate bias, counts were performed blindly by two independent researchers.

\section{STATISTICAL ANALYSIS}

The percentage of papillae containing immunoreactive fibres for PGP and for each neuropeptide is shown as the mean (SEM). The proportion of positively innervated papillae in biopsy specimens from each patient was counted. Comparison of the difference in the density of innervation between groups was made using analysis of variance. A level of probability of 0.05 or less was considered to be significant. Comparison of counts made by two observers was made using the measurement of agreement between two observers described by Brennan and Silman. ${ }^{31}$

\section{Results}

Oesophageal biopsy specimens were $2-4 \mathrm{~mm}$ long and 1-2 $\mathrm{mm}$ deep. All specimens consisted of mucosal squamous epithelium with the majority also containing some lamina propria. A total of 526 sections examined contained papillae, with a mean of 3.93 (SD 2.98) papilla profiles per section. There was no significant difference in the number of identifiable papillae in inflamed $(n=151$; mean $=4.03$ (2.58)) and non-inflamed (including healed previously inflamed $)$ mucosa $(n=375$; mean $=$ $3.6(2.32))$ biopsy specimens.

PGP

It was possible to detect positively labelled immunoreactive fibres to the general nerve marker PGP. An immunoreactive plexus of nerve fibres was seen running in the squamous epithelial layers around the papillae (fig 1). The fibres appeared to be varicose. No immunoreactive nerve cell bodies were identified. There were no nerve fibres seen projecting into the squamous epithelium.

\section{NEUROPEPTIDE MARKERS}

Nerve fibres immunoreactive to each nerve marker studied were seen in the subepithelial plexus. Not all papillae however contained fibres immunoreactive for each of the nerve markers studied. The density of innervation was heterogeneous with some papillae containing several fibres and others only one.

DENSITY OF INNERVATION

The percentage of papillae containing positively staining immunoreactive fibres was calculated by two independent observers. The mean difference in counts was $-2 \%$ (95\% confidence interval $-4 \%$ to $+1 \%$ )

Table 1 shows the percentage of papillae containing immunoreactive fibres for each of the patient groups. In the controls, the greatest proportion of papillae contained PGP and NPY immunoreactive fibres. The proportion of papillae containing fibres immunoreactive to SP was similar to that containing CGRP and VIP immunoreactive fibres.

There was a significant increase in the proportion of papillae containing PGP (fig $2 \mathrm{~A}, \mathrm{~B})$ and VIP immunoreactive fibres, but not the other tested neurotransmitters, in the inflamed compared with control biopsy specimens.

Non-inflamed and healed tissue did not significantly differ from control specimens in the proportion of positive immunoreactive fibres for PGP or any of the neurotransmitters studied.

\section{Discussion}

This study has shown that it is possible to study the oesophageal epithelial and subepithelial innervation in man using endoscopically obtained biopsy specimens in a clinical setting. Previous studies of the human oesophageal innervation have been limited to full thickness surgically resected or autopsy specimens because of the difficulties in obtaining reliable tissue specimens. ${ }^{28} 3233$

By use of oesophageal epithelial biopsy specimens this study has shown a network of subepithelial nerves in patients with reflux and in healthy individuals. There has previously been limited information about this plexus 
although the presence of a subepithelial plexus of nerve fibres has been reported previously both in animals and in man. ${ }^{28} 34$ In our study, these fibres did not appear to penetrate the epithelial cell layer, although the latter has previously been described in animals. The likely origin of the subepithelial plexus of fibres was not determined in our study due to the limited depth of the biopsy specimens. No nerve cell bodies were identified in this subepithelial plexus. Animal studies have suggested that the subepithelial nerves arise largely from the intrinsic enteric nervous system. ${ }^{36}$

Most of the information about the function of epithelial innervation of the gastrointestinal tract is obtained from animal studies and the application of this to human epithelial function is therefore limited. The role of the subepithelial plexus in the oesophageal mucosa is unknown. Wattchow et al suggested that these subepithelial fibres may be sensory or sensorimotor ${ }^{28}$ with cell bodies in the submucosal or myenteric plexus. In the oesophagus of man submucosal ganglia are sparse, ${ }^{32}$ in contrast with their increased number in the more distal gut.

In this study the oesophageal mucosa contained nerve fibres immunoreactive to all the tested neuropeptides. These findings corroborate those of Wattchow et al who showed the presence of VIP, NPY, and SP immunoreactive nerve fibres in the normal human oesophageal mucosa of full thickness oesophageal preparations. In that study, although CGRP was present in the muscle layers and submucous plexus, no CGRP was shown in the oesophageal mucosa. ${ }^{28}$

Substance P functions as both a sensory and motor neurotransmitter ${ }^{37}$ and is colocalised with CGRP in afferent gut neurones. ${ }^{38}{ }^{39}$ In the human gastrointestinal tract $\mathrm{SP}$ is found in association with mucosal and submucosal blood vessels ${ }^{40}$ and is also found to have a role in immunomodulation. ${ }^{41}$ An increase in mucosal substance $\mathrm{P}$ has been reported in inflammatory conditions of the gastrointestinal tract $^{42-44}$ in both man and animals in both chronic and acute inflammatory conditions although other reports have shown no change ${ }^{45}$ or a reduction. ${ }^{46}$ The inflammatory changes in reflux oesophagitis are relatively mild compared with conditions such as inflammatory bowel disease. This may explain the lack of change in substance $P$.

CGRP is a powerful vasodilator. ${ }^{47}$ It appears to be contained largely in extrinsic enteric nerves ${ }^{48} 49$ and is involved in mucosal response to inflammation. ${ }^{50}$

VIP is involved in mucosal blood flow in response to inflammation and also in secretion of water and electrolytes from the intestinal mucosa. ${ }^{51}$ VIP receptors have been found on the basolateral membrane of rat and rabbit enterocytes ${ }^{52} 53$ and release of VIP from enteric neurones results in activation of adenylate cyclase in intestinal mucosal epithelial cells. ${ }^{51}$ Adenylate cyclase regulates sodium and chloride ion exchange and VIP containing neurones in the oesophageal mucosa could mediate a similar pathway. Release of VIP from subepithelial nerves could also mediate an increase in epithelial germinal cell proliferation, leading to the observed elongation of the papillae and the thickening of the germinal cell layer seen in gastro-oesophageal reflux disease (GORD). ${ }^{14}$ Further studies have suggested the role of VIP in motor or sensorimotor nerves in gastrointestinal mucosa. ${ }^{28} 54$ The changes in VIP which we observed may play an important role in the response to acid exposure as part of the inflammatory response.

Neuropeptide Y has been shown in relation to the sympathetic innervation of the human gastrointestinal tract. ${ }^{556}$ Sympathetic, as opposed to vagal, changes have not been shown in reflux disease.

There was no difference in the proportion of papillae containing nerve fibres immunoreactive to each of the nerve markers studied in the biopsy specimens from non-inflamed mucosa in patients with oesophagitis when compared with controls. This suggests that patients with GORD do not have alterations in the underlying structure of the oesophageal mucosal innervation, at least for the neurotransmitters studied.

In biopsy specimens taken from the inflamed oesophageal mucosa between erosions, however, there was an increase in the proportion of papillae containing nerve fibres immunoreactive to PGP and VIP. These changes were not apparent in specimens taken from the healed mucosa of patients with reflux disease. It appears that the observed changes in oesophageal innervation occur secondary to the mucosal inflammation caused by acid reflux. The increase in fibres with PGP-like immunoreactivity suggests that there is an increase in the absolute number of nerve fibres in the subepithelial plexus in the inflamed tissue. VIP within these fibres could account for the increases in the proportion of VIP immunoreactive papillae. Increases in the quantity of VIP within existing nerves however could also account for these changes as increased intensity of fluorescence would allow more of these immunoreactive fibres to become visible on light microscopy.

Changes in enteric innervation have been observed in other inflammatory gastrointestinal disorders, ${ }^{57}$ although the observed changes have been variable. In inflammatory bowel disease the level of mucosal VIP has been reported to be both increased ${ }^{58} 59$ and decreased. ${ }^{456061}$ These findings have been based on assay of neuropeptides in mucosa obtained from full thickness resection specimens or rectal mucosal biopsy specimens in inflammatory bowel disease, which are likely to include the innervation of blood vessels in the lamina propria. As the nerve fibres shown in our study were exclusively associated with the subepithelial layer and not with blood vessels it is unlikely that the changes we observed were directly associated with an alteration in mucosal blood flow.

Using epithelial biopsy specimens it is not possible to study the levels of $m R$ NA for VIP in the cell bodies which would indicate whether increased synthesis of VIP was occurring. 
Using the proportion of papillae containing positively staining immunoreactive fibres provides a reasonable basis against which to assess changes in innervation within the mucosa. As the quantitation of immunoreactivity is expressed as a proportion of all the identified papillae, differences in the number of papillae present in each section do not influence the result. The histological response to acid reflux is characterised by elongation of the papillae and a thickening of the basal cell layer ${ }^{15} 30$ which reverses on reduction of oesophageal acid exposure. ${ }^{15}$ Although an increase in papilla length in biopsy specimens from inflamed oesophagus could increase the likelihood of including a papilla within a biopsy section, only those papillae whose base was present were counted. Shorter papillae were therefore included with equal likelihood as the longer ones seen in inflamed oesophageal mucosa.

The use of other methods to determine oesophageal epithelial innervation quantitatively were not used because of the variable depth of the oesophageal biopsy specimens. The differences in the tissue content in a single biopsy section precluded the use of image analysis and assay of the neuropeptide content of a single specimen. Because the specimens obtained were found to be of variable depth, only those which included the epithelium and lamina propria were included in the analysis. Due to the small size of the specimens, all had to be sectioned prior to use. A histochemical method of assessment of innervation was therefore required. Oesophageal epithelial changes in response to gastro-oesophageal reflux are patchy. To minimise sampling error, specimens were always taken a constant distance proximal to the squamocolumnar junction and areas of visible epithelial ulceration were avoided. In addition, two specimens were taken from each area in each subject.

In summary, we have found evidence for an increase in VIP in the mucosa of biopsy specimens from the inflamed oesophagus in patients with reflux oesophagitis. These changes were not seen in the non-inflamed mucosa from these patients or in the healed mucosa of patients with treated oesophagitis. This suggests that the observed changes are secondary to inflammation. The technique described should enable further study of the epithelial innervation in oesophageal reflux disease.

1 Dutta SK, Matossian HB, Meirowitz RF, Vaeth J. Modulation of salivary secretion by acid infusion in the distal tion of salivary secretion by acid infusion in the dista

2 Sarosiek J, Rousk RM, Prasack R, et al. The effect of mucin secretion in healthy individuals. Am f Med Sci 1994; mucin secretio

3 Namiot Z, Sarosiek J, Rourk R, et al. Human esophageal secretion: mucosal response to luminal acid and pepsin. Gastroenterology 1994;106:973-81.

4 Hamilton $\mathrm{BH}$, Orlando RC. In vivo alkaline secretion by mammalian esophagus. Gastroenterology 1989;97:640-8.

5 Meyers RL, Orlando RC. In vivo bicarbonate secretion by human esophagus. Gastroenterology 1992;103:1174-8.

6 Brown CM, Snowdon CF, Slee B, et al. Measurement of bicarbonate output from intact human oesophagus. Gut 1993;34:872-80.

7 Hopwood D. Histochemical studies of mucosubstances and lipids in normal human esophageal epithelium. Histochem $\mathcal{f}$ 1977;9:153.

8 Lacy E. The esophageal mucosal barrier: structural correlates [abstract]. Gastroenterology 1989;96:A281.
9 Greenwood B, Mantle M. Mucin and protein release in the rabbit jejunum: effects of bethanecol and vagal nerve rabbit jejunum: effects of bethanecol and va
stimulation. Gastroenterology 1992;103:496-505.

10 Namiot Z, Sarosiek J, Marcinkiewicz M, et al. Declined human esophageal mucin secretion in patients with severe reflux esophagitis. Dig Dis Sci 1994;39:2523-9.

11 Namiot Z, Rourk RM, Piascik R, et al. Interrelationship between esophageal challenge with mechanical and chemical stimuli and salivary protective mechanisms. Am $\mathcal{F}$ Gastroenterol 1994;89:581-7.

12 Bass BL, Schweitzer EJ, Harman JW, et al. $\mathrm{H}^{+}$back-diffusion interferes with intrinsic reactive regulation of esophageal mucosal blood flow. Surgery 1984;96:404-13.

13 Livstone EM, Sheahan DG, Behar J. Studies of esophageal epithelial proliferation in patients with reflux esophagitis. Am 7 Gastroenterol 1977;73:1315-19.

14 Ismail-Beigi F, Pope CE. Distribution of the histological changes of gastro-oesophageal reflux in man. Gastroenterology 1974;66:1109-13.

15 Johnson LF, Demeester TR, Hagitt RC. Esophageal epithelial response to gastroesophageal reflux. Dig Dis 1978;23 498-509.

16 Higgs RH, Castell DO, Eastwood GL. Studies in the mechanism of esophagitis-induced lower esophageal sphincter hypotension in cats. Gastroenterology 1976;71:51-6.

17 Eastwood GL, Castell DO, Higgs RH. Experimental esophagitis in cats impairs lower esophageal sphincter pressure. Gastroenterology 1975;69:146-53.

18 Ahtaridis G, Snape WJ, Cohen S. Lower esophageal sphincter pressure as an index of gastroesophageal reflux. Dig Dis Sci 1981;26:993-8.

19 Reynolds JC, Ouyang A, Cohen S. A lower esophageal sphincter reflex involving substance P. Am f Physiol 1984;246: G346-54.

20 Biancani P, Billet G, Hillemeier C, et al. Acute experimental esophagitis impairs signal transduction in cat lower sophageal sphincter circular muscle. Gastroenterology ;03:1199-206

21 Salapatek AFM, Diamant NE. Assessment of neural inhibition of the lower esophageal sphincter in cats with esophagitis. Gastroenterology 1993;104:810-18

$22 \mathrm{Ny} \mathrm{L}$, Alm P, Ekstrom P, et al. Nitric oxide synthasecontaining, peptide-containing; and acetylcholinesterasepositive nerves in the cat lower esophagus. Histochem $\mathcal{F}$ 1994;26:721-33.

23 Corraziari E, Bontempo I, Anzini F, et al. Motor activity of the distal oesophagus and distal gastro-oesophageal reflux. Gut 1984;25:7-13.

24 Baldi F, Ferarini F, Balestra R, et al. Oesophageal motor events at the occurrence of acid reflux and during endogenous acid exposure in healthy subjects and in patients with oesophagitis. Gut 1985;26:336-41.

25 Bontempo I, Piretta L, Corazziari E, et al. Effects of intraluminal acidification on oesophageal motor activity. Gut minal acidificatio

26 Bass BL, Trad KS, Harmon JW, et al. Capsaicin sensitive nerves mediate esophageal mucosal protection. Surgery 1991;110:119-25

27 Ollyo J-B, Fontolliet Ch, Brossard E, et al. La nouvelle classification de Savary des oesophagites de reflux. Acta Endoscopica 1992;22:309-20.

28 Wattchow D, Furness J, Costa M, et al. Distributions of neuropeptides in the human esophagus. Gastroenterology 1987;93:1363-71

29 Keast JR, Furness JB. Distribution of peptide-containing neurons and endocrine cells in the rabbit gastrointestinal tract with particular reference to the mucosa. Cell Tissue Res 1987;248:565-77.

30 Ismail-Beigi F, Horton PF, Pope CE. Histologic consequences of gastroesophageal reflux in man. Gastroenterology quences of gastroesc

31 Brennan P, Silman A. Statistical methods for assessing observer variability in clinical measures. $B M F$ 1992;304 $1491-4$

32 Ferri G-L, Thomas EA, Soimero L, et al. Intramural distribution of immunoreactive vasoactive intestinal polypepide, substance P, somatostatin and mammalian bombesin in the esophago-gastro-pyloric region of the human gut. Cell Tissue Res 1989;256:191-7.

33 Singaram C, Sengupta A, Sweet MA, et al. Nitrinergic and peptidergic innervation of the human oesophagus. Gut 1994;35:1690-6.

34 Robles-Chillida E, Rodrigo J, Mayo I, et al. Ultrastructure of free-ending nerve fibres in oesophageal epithelium. If Anat 1981;133:227-33.

35 Rodrigo J, Hernandez C, Vidal M, et al. Vegetative innervation of the oesophagus. III. Intraepithelial endings. Acta Anat Basel 1975;92:242-58.

36 Keast JR, Furness JB, Costa M. Origins of peptide and norepinephrine nerves in the mucosa of the guinea pig small intestine. Gastroenterology 1984;86:637-44.

37 Domoto T, Jury J, Berezin I, et al. Does Substance P comediate with acetylcholine in nerves of opossum oesophageal muscularis mucosa? Am f Physiol 1983;245:G19-28.

38 Sternini C, Reeve JR, Brecha N. Distribution and characterisation of calcitonin gene-related peptide immunoreactivity in the digestive system of normal and capsaicin treated rats. Gastroenterology 1987;93:852-62.

39 Parkman HP, Reynolds JC, Elfman KS, et al. Calcitonin gene-related peptide: a sensory and motor transmitter in the feline lower oesophageal sphincter. Regul Pept 1989;25: 131-46.

40 Ferri GL, Botti P, Billiotti G, et al. VIP-, substance P and met-enkephalin-immunoreactive innervation of the human 
gastroduodenal mucosa and Brunner's glands. Gut 1984; 25:948-52.

41 Scichitano $R$, Biennenstock J Stanisz AM. In vivo modulation by the neuropeptide substance P. Immunology 1988;63: $733-5$.

42 Goldin E, Karmeli F, Selinger Z, et al. Colonic substance P levels are increased in ulcerative colitis and decreased in chronic severe constipation. Dig Dis Sci 1989;34:754-7.

43 Holtzer P. Local effector functions of capsaicin-sensitive sensory nerve endings. Involvement of tachykinins calcitonin gene-related peptide and other neuropeptides. Neuroscience 1988;24:739-68.

44 Holzer P, Pabst MA, Lippe IT. Intragastric capsaicin protects against aspirin-induced lesion formation and bleeding in the rat gastric mucosa. Gastroenterology 1989;96:1425-33

45 Koch TR, Carney A, Go VWL. Distribution and quantitation of gut neuropeptides in normal intestine and .

46 Reinshagen M, Patel A, Sottili M, et al. Protective function of extrinsic sensory neurons in acute rabbit experimental colitis. Gastroenterology 1994;106:1208-24.

47 Meleagros L, Ghatei MA, Bloom SR. Release of vasodilator, but not vasoconstrictor, neuropeptides and of enteroglucagon by intestinal ischaemia/reperfusion in the rat. Gut 1994;35:1701-6.

48 McGregor GP, Conlon JM. Regulatory peptide and serotonin content and brush-border enzyme activity in the rat gastrointestinal tract following neonatal treatment with capsaicin; lack of effect on epithelial markers. Regul Pept 1991;32:109-19.

49 Raybould HE, Sternini C, Eysselein VE, et al. Selective ablation of spinal afferent neurons containing CGRP attenuates hyperaemic response to acid. Peptides 1992:13: 249-54.

50 Eysselein VE, Reinshagen M, Cominelli F, et al. Calcitonin gene-related peptide and substance $\mathrm{P}$ decreases in the rabbit colon during colitis. A time study. Gastroenterology 1991:101:1211-99.
51 Schwartz CI, Kimberg DV, Sheerin HE, et al. Vasoactive intestinal peptide stimulation of adenylate cyclase and active electrolyte secre

52 Binder HJ, Lemp GF, Gardner JD. Receptors for vasoactive intestinal peptide and secretin on small intestinal epithelial cells. Am f Physiol 1980;238:G190-6.

53 Dharmsathaphorn K, Harms V, Yamashiro J, et al. Preferential binding of vasoactive intestinal polypeptide to basolateral membrane of rat and rabbit enterocytes. 7 Clin Invest 1983;71:27-35.

54 Uddman R, Alumets J, Edvinsson L, et al. Peptidergic (VIP) innervation of the esophagus. Gastroenterology 1978;75:5-

55 Wattchow DA, Furness JB, Costa M. Distribution and co-existence of peptides in nerve fibres of the human gastrointestinal tract. Gastroenterology 1988;95:32-41.

56 Milner P, Crowe R, Kamm MA, et al. Vasoactive intestinal polypeptide levels in sigmoid colon in idiopathic constipation and diverticular disease. Gastroenterology 1990;99:66675.

57 Belai A, Boulos PB, Robson T, et al. Neurochemical coding in the small intestine of patients with Crohn's disease. Gut 1997;40:767-74.

58 O'Morain C, Bishop AE, McGregor GP, et al. Vasoactive intestinal peptide concentrations and immunocytochemical studies in rectal biopsies from patients with inflammatory bowel disease. Gut 1984;25:57-61.

59 Bishop AE, Polak JM, Bryant MG, et al. Abnormalities of vasoactive intestinal polypeptide-containing nerves in Crohn's disease. Gastroenterology 1980;79:853-60.

60 Mazumdar S, Moy Das K. Immunocytochemical localisation of vasoactive intestinal peptide and substance $\mathrm{P}$ in the colon from normal subjects and patients with inflammatory bowel disease. Am 7 Gastroenterol 1992;87:176-81.

61 Sjolund K, Schaffalitzky de Muckadell OB, Fahrenkrug J, et al. Peptide containing nerve fibres in the gut wall in Crohn's disease. Gut 1983;24:724-33. 